\title{
Penile preserving surgery in penile cancer management
}

\section{Dear Editor,}

Penile cancer is a condition that accounts for approximately $0.4 \%$ of cancers among Singapore males. ${ }^{1}$ Overall, this is an uncommon cancer with higher rates in developing countries (2.8-6.8 per 100,000) compared to Western countries (as low as 0.3 per 100,000$).^{2}$ However, in the UK, which is a developed country, there was a recent report of an increase in incidence rates from 1.10 to 1.33 per $100,000 .^{3}$ This was attributed to the greater exposure to sexually transmitted oncogenic human papilloma viruses, which are associated with up to $40 \%$ of penile cancer cases. ${ }^{2}$ The most common site for penile cancer is the glans $(48 \%)$, followed by prepuce $(21 \%)$, glans and prepuce $(9 \%)$, coronal sulcus $(6 \%)$ and the shaft $(<2 \%){ }^{2}$

Patients with invasive penile cancer typically receive partial or total penectomy as treatment for their primary cancer. The amputation surgery plus bilateral inguinal lymph node dissection for lymph node management bring about significant morbidity to the patient. In Singapore, 2 separate case series reported a total of 46 (7 and 39 respectively) patients with penile cancer. Of these cases, $30(65 \%)$ were treated with amputation surgery, $12(26 \%)$ were treated with excisional biopsy, 2 (4\%) were treated with primary radiotherapy, $1(2 \%)$ was treated with palliative chemotherapy and $1(2 \%)$ was treated with primary chemotherapy for lymphoma histology. ${ }^{1,4}$

Penile preserving surgery is increasingly recognised as a standard of care for early penile cancers due to the improved functional and cosmetic outcomes compared to amputation surgery. Specifically, glansectomy should be considered for T1/T2 cancers involving the glans penis. ${ }^{5}$ We describe the first locally reported case of glansectomy and split skin graft (SSG) reconstruction and discuss the rationale and benefits of penile preserving surgery.

A 42-year-old uncircumcised Chinese man who smoked cigarette for 20 years presented with a $3 \mathrm{~cm}$ warty lesion involving the prepuce and glans from 7 to 12 o'clock position (Fig. 1A). He had no palpable inguinal lymph nodes. A limited circumcision with incision biopsy showed a well-differentiated squamous cell carcinoma. Local staging using MRI penis with artificial erection showed that the disease did not involve the corpora cavernosum $(\leq \mathrm{T} 2)$. He underwent glansectomy with split skin graft reconstruction similar to the technique described by Parnham et al. ${ }^{6}$

The final histology showed well-differentiated invasive squamous cell carcinoma involving the corpus spongiosum and a $3 \mathrm{~mm}$ negative margin (pT2G1). The patient had a partial graft loss at 2 weeks that healed without any surgical intervention. He declined surgical staging of his inguinal lymph nodes. Functionally, he had a stretched penile length loss of $2 \mathrm{~cm}$ from $9 \mathrm{~cm}$ to $7 \mathrm{~cm}$. He had a normal post-operative erectile function and had resumed sexual activities at 6 months. He voided in a standing position and he was not bothered by spraying of urine. There was no local recurrence or distant metastasis 10 months post-operation (Fig. 1B).
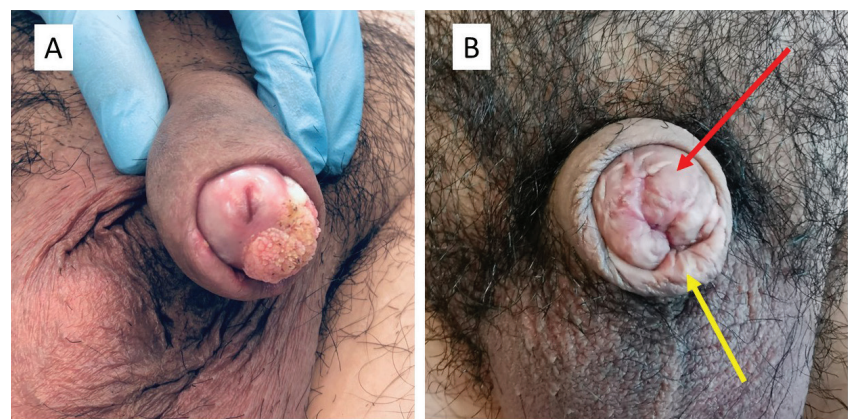

Fig. 1. A: Pre-operative photo. B: Post-operative neo-glans at 10 months. Yellow arrow indicates neo-meatus. Red arrow indicates skin graft coverage of the corpus cavernosa.

TNM reclassification of corpus cavernosum involvement from $\mathbf{T} 2$ to $\mathbf{T 3}$. Two recent refinements to the penile cancer management guidelines have provided impetus towards increasing the utility of penile preserving surgery. Firstly, the eighth edition of the Tumor-Node-Metastasis staging classification for penile cancer published around 2016 has reclassified tumour invasion into corpus cavernosum as T3. While previously grouped with $\mathrm{T} 2$, studies have shown that corpus cavernosum invasion is associated with higher inguinal lymph node involvement $(48.6-52.5 \%$ versus $33-35.8 \%$ ) and worse survival when compared to corpus spongiosum invasion. ${ }^{7}$ With this update, there is clearer distinction in oncological outcomes for patients with $\leq \mathrm{T} 2$ disease who are eligible for penile preserving surgery. Moreover, penile MRI with artificial erection has been shown to be an accurate modality in predicting corpus cavernosum invasion, achieving sensitivity of $82.1 \%$ and specificity of $73.6 \%{ }^{8}$ 
Acceptance of a shorter negative margin. Secondly, the traditional $2 \mathrm{~cm}$ surgical margin for penile cancer has been challenged by recent studies. When the oncological outcome of a large series of 179 patients treated with penile preserving surgery was reviewed, a surgical margin of $5 \mathrm{~mm}$ was considered adequate. ${ }^{9}$ The European Association of Urology now recommends a grade-based differentiated approach, with $3 \mathrm{~mm}$ for grade $1,5 \mathrm{~mm}$ for grade 2 , and $8 \mathrm{~mm}$ for grade $3 .{ }^{10}$ With this change to the required width of negative surgical margins, more patients become candidates for penile preserving surgery.

Oncological outcomes comparable to amputation surgery. There has been concern with higher rate of local recurrence following penile preserving surgery. However, more recent series revealed local recurrence rates of $4-9.3 \%$, which were comparable to that of partial penectomy. ${ }^{6,11,12}$ The largest reported cohort of glansectomy by Parnham et al. looked at 177 patients who underwent glansectomy between 2005 and 2016 . They reported a $9.3 \%$ local recurrence during a median follow-up of 41.4 months; cancer specific mortality was $10.7 \%$ and overall survival was $83 \%$. The proportion of Clavien Grade 3 complications including graft loss and meatal stenosis was $9 \%{ }^{6}$ Veeratterapillay et al. reported 65 patients who underwent penile preserving surgery including total glansectomy, glanuloplasty, partial glansectomy, glans resurfacing and distal penectomy with glans reconstruction with a median follow-up of 40 months. They found local recurrence in 4 patients $(6 \%)$ despite $72 \%$ having intermediate or poorly differentiated tumours and 30\% with T2 disease. ${ }^{11}$

Improved functional outcomes. A systematic review by Maddineni that examined patients' quality of life post-surgery for penile cancer revealed that up to $40 \%$ of patients had a poorer quality of life, and up to two-thirds of patients reported a reduction in sexual function. ${ }^{13}$ On the other hand, patients who underwent glansectomy with SSG were able to retain erectile, orgasmic and ejaculatory function, even with reduced glans sensation. ${ }^{14}$ Smith et al. also reported that most patients who were sexually active pre-operatively had been able to continue sexual intercourse after glansectomy. The procedure resulted in maximum phallic length preservation and a cosmetically satisfactory appearance. ${ }^{12}$ Studies that directly compare the oncological and functional outcomes after penile preserving surgery and partial penectomy are eagerly awaited.

In conclusion, penile preserving surgery such as glansectomy with SSG reconstruction should be considered for all penile cancer $\leq \mathrm{T} 2$ that does not involve the corpus cavernosum. This procedure is associated with a comparable oncological outcome and an acceptable complication rate. It potentially offers better cosmetic satisfaction, as well as improved psychosexual and urinary function.

\section{REFERENCES}

1. Tan TW, Chia SJ, Chong KT. Management of penile cancer in a Singapore tertiary hospital. Arab J Urol 2017;15:123-30.

2. Douglawi A, Masterson TA. Updates on the epidemiology and risk factors for penile cancer. Transl Androl Urol 2017;6:785-90.

3. Arya M, Li R, Pegler K, et al. Long-term trends in incidence, survival and mortality of primary penile cancer in England. Cancer Causes Control 2013;24:2169-76.

4. Lau WD, Ong CH, Lim TP, et al. Penile cancer: A local case series and literature review. Singapore Med J 2015;56:637-40.

5. Hegarty PK, Eardley I, Heidenreich A, et al. Penile cancer: Organ-sparing techniques. BJU Int 2014;114:799-805.

6. Parnham AS, Albersen M, Sahdev V, et al. Glansectomy and Split-thickness Skin Graft for Penile Cancer. Eur Urol 2018; 73:284-9.

7. Paner GP, Stadler WM, Hansel DE, et al. Updates in the Eighth Edition of the Tumor-Node-Metastasis Staging Classification for Urologic Cancers. Eur Urol 2018;73:560-9.

8. Hanchanale V, Yeo L, Subedi N, et al. The accuracy of magnetic resonance imaging (MRI) in predicting the invasion of the tunica albuginea and the urethra during the primary staging of penile cancer. BJU Int 2016;117:439-43.

9. Philippou P, Shabbir M, Malone P, et al. Conservative surgery for squamous cell carcinoma of the penis: Resection margins and long-term oncological control. J Urol 2012;188:803-8.

10. Hakenberg OW, Minhas ES, Necchi A, et al. European Association of Urology Guidelines. 2020 Edition. In: Vol presented. European Association of Urology Guidelines Office, 2020. Available at: http:// uroweb.org/guideline/penile-cancer/. Accessed on 1 November 2020.

11. Veeratterapillay R, Sahadevan K, Aluru P, et al. Organ-preserving surgery for penile cancer: Description of techniques and surgical outcomes. BJU Int 2012;110:1792-5.

12. Smith Y, Hadway P, Biedrzycki O, et al. Reconstructive Surgery for Invasive Squamous Carcinoma of the Glans Penis. Eur Urol 2007;52:1179-85.

13. Maddineni SB, Lau MM, Sangar VK. Identifying the needs of penile cancer sufferers: A systematic review of the quality of life, psychosexual and psychosocial literature in penile cancer. BMC Urol 2009;9:1-6.

14. Morelli G, Pagni R, Mariani C, et al. Glansectomy with split-thickness skin graft for the treatment of penile carcinoma. Int $\mathrm{J}$ Impot Res 2009;21:311-4.

Mon M Oo, ${ }^{1}$ MRCS, Jeffrey J Leow, ${ }^{1} M P H$, Weida Lau, ${ }_{F R C S}$

${ }^{1}$ Department of Urology, Khoo Teck Puat Hospital, National Healthcare Group, Singapore

Correspondence: Dr Weida Lau, Department of Urology, Khoo Teck Puat Hospital, 90 Yishun Central, Singapore 768828.

Email: lau.weida@gmail.com 